\title{
O site educativo de português como língua materna: um olhar da lingüística aplicada crítica
}

\author{
Noadia Íris da Silva (SILVA, Noadia Íris da) \\ Mestre em Lingüística pela Universidade Federal de Pernambuco -UFPE \\ noadiairis@hotmail.com \\ Beth Marcuschi (MARCUSCHI, Beth) \\ Doutora em Linguística. Professora da graduação e da pós-graduação no Departamento \\ de Letras da Universidade Federal de Pernambuco - UFPE \\ beth.marcuschi@gmail.com
}

\begin{abstract}
Resumo
O desenvolvimento da rede mundial de computadores tem contribuído para o surgimento de novas formas de socialização do conhecimento favorecendo a educação a distância, fenômeno ao qual se vincula uma grande procura de cursos de português. Nesse cenário, o site educativo tem se transformado num importante recurso de ensino/aprendizagem, sendo procurado por usuários pelos mais diferentes motivos. Esse movimento, todavia, não tem recebido a devida atenção da academia no sentido de estudar os objetivos, a qualidade e os ganhos potenciais que são oferecidos aos alunos/internautas em tais espaços pedagógicos. Neste estudo, visamos a analisar sites de ensino de português quanto aos propósitos perseguidos, suas concepções de língua e gramática através da realização de uma pesquisa empírica com três desses sites. Nosso corpus é composto pela apreciação dos conteúdos veiculados e a descrição das aulas e atividades propostas nos sites. Nossos resultados apontam para a existência de contradições entre os conteúdos declarados e os efetivamente abordados, além de uma tendência redutora de conceber a língua como um código e a gramática como um conjunto de regras de uso da norma culta. Assim, chamamos a atenção do leitor para a cautela necessária ao adotar sites como recurso para o ensino/aprendizagem de língua.
\end{abstract}

Palavras-chave: ensino a distância, língua portuguesa, site educativo.

\begin{abstract}
Development of the computer global network has contributed to the emergence of new ways to socialize knowledge, encouraging the phenomenon of distance education, elearning, which is generating a large demand for Portuguese courses for native speakers. In this scenario, educational websites have become important teaching/learning resources, sought by users for the most varied reasons. This movement, however, has not received enough attention in academia regarding the objectives, quality, and potential gains that are offered to students in these spaces. An empirical study was carried out on three Portuguese language teaching sites, to examine their objectives and conceptions of language and grammar. Our corpus includes the content and the description of classes and activities on these sites. Results indicate contradictions between the content proposed and that which is effectively addressed, and a reduction
\end{abstract}


tendency in designing the language as a code and its grammar as a set of rules. We thus recommend caution in using websites as resources for language teaching/learning.

Keywords: e-learning, Portuguese language, educational website.

\section{Introdução}

A world wide web tem contribuído para a criação de novos espaços de aprendizagem fora do ambiente tradicional da sala de aula, ao propiciar acesso ilimitado a fontes de pesquisa. Santos (2007, p. 278), baseando-se em estimativas da universidade de Berkeley, EUA, afirma que, no ano de 2003, “existia na internet mais de 500 bilhões de documentos cobertos - apenas em parte, pelos cinco principais buscadores do mundo: Yahoo!, Google, Starmedia, Sapo, Ukplus”.

Esse “dilúvio da informação" (cf. LÉVY, 2000), disponibilizado na rede mundial de computadores, tem favorecido o desenvolvimento de uma nova forma de aprendizagem mediada por computador denominada de ensino a distância, e-learning. Nas palavras de Vidal (2002, p. 16):

A formação presencial tem, desde há poucos anos, um novo concorrente. O $e$ learning, com suas novas potencialidades, começa a ganhar cada vez mais aderentes. De acordo com a UNESCO (2000), mais de 84 milhões de jovens de todo mundo seguem seus estudos pela Internet podendo este número chegar aos 160 milhões em 2005.

Um dos principais recursos do e-learning é o site com fins educativos, instrumento que pode ser usado tanto para estudo auto monitorado, quanto com auxílio de professores em projetos específicos. Atualmente, tem crescido no nosso país o número de sites que oferecem subsídios para a prática pedagógica da língua portuguesa como língua materna, seja através do oferecimento de cursos sistemáticos ou da exposição de conteúdos referentes aos conhecimentos sobre a língua, respondendo à necessidade de internautas /estudantes virtuais e até de professores que procuram tais sites pelos mais variados motivos. De acordo com Dotta (2003, p. 6), "desde o advento da World Wide Web, sites denominados educacionais têm se proliferado pela internet. A maioria deles é utilizada indiscriminadamente por professores que pretendem inserir novas tecnologias no processo de ensino-aprendizagem”.

Essa procura, no entanto, não tem despertado o devido interesse dos pesquisadores brasileiros, no sentido de serem investigados os objetivos, a qualidade e os ganhos potenciais que são disponibilizados aos alunos/internautas nesses espaços pedagógicos. Há poucos trabalhos que exploram essa temática, nos quais fica patente o consenso de que o material veiculado pela internet precisa ser cautelosamente examinado antes de se tornar recurso de ensino/aprendizagem, tendo em vista que, boa parte dele, é de procedência duvidosa. Conforme Carvalho (2004, p. 12), “a exploração de sites em contexto educativo constitui um requisito na sociedade da informação. No entanto, [...] nem todos os sites têm qualidade ou são adequados para o contexto educativo, pelo que devem ser analisados previamente”.

Assim, este trabalho constitui-se numa pesquisa empírica de três sites educativos de língua portuguesa como língua materna, analisados quanto aos objetivos perseguidos 
para o ensino de língua e quanto às concepções de língua e gramática subjacentes às atividades propostas.

\section{Sobre os sites educativos}

O Dicionário Houaiss da Língua Portuguesa (2001, p. 2587) define site como "local na internet identificado por um nome de domínio, constituído por uma ou mais páginas de hipertexto, que podem conter textos, gráficos e informações em multimídia”. Já Carvalho (2004, p. 3) afirma:

Na perspectiva do utilizador, um site é constituído por páginas, ficheiros diversos e hiperligações, podendo estas ser internas (no site) e externas (para outros sites). A página inicial de um site, designada também como "home page" ou "home", contém, geralmente, informações e hiperligações pertinentes que possibilitam ao utilizador aceder a outras informações do site.

A princípio, todo site pode ser usado com fins educativos, de acordo com os interesses do internauta, mas há aqueles cujo objetivo explícito é o de promover conhecimento sobre determinados domínios do saber, que se autodenominam educativos. Contudo, como a publicação de páginas na internet praticamente não é submetida a mecanismos reguladores oficiais, o utilizador da rede não pode confiar $a$ priori na informação disponível, precisando de indicadores que o auxiliem na garantia da informação que acessa, mesmo que ela parta de um site denominado educativo. Por isso, especialistas, tais como Beck (1997), Alexander e Tate (1999), Grassian (2000), Tilman (2003) e Richmond (2003) entre outros ${ }^{1}$ têm se dedicado à construção de critérios que possam indicar a qualidade de sites pedagógicos.

Franco (2000, p. 3) aponta algumas das questões discutidas por tais autores: "Entre as interrogações mais comuns, partilhadas pelos especialistas de diferentes domínios científicos, constam: a qualidade do site, o seu valor educativo, o seu papel na aprendizagem de tópicos curriculares e na promoção do trabalho colaborativo [...]”.

Por sua vez, Carvalho (2006) propõe a observação de critérios de nove diferentes dimensões no sentido de atestar a qualidade de sites educativos. Na avaliação dessa autora, os sites devem ser investigados quanto a identidade, usabilidade, rapidez de acesso, níveis de interatividade, fiabilidade das informações fornecidas, atividades que propõem, possibilidade de edição colaborativa on-line e espaço de partilha e comunicação que disponibilizam a seus usuários. No estudo da língua materna, acrescentaríamos a essas categorias de análise a investigação dos objetivos perseguidos para o ensino de língua e da concepção de língua norteadora das atividades recomendadas pelos sites.

\section{A procura por cursos de português como língua materna em sites}

Para encontrar o material que constituiria o corpus de nossa pesquisa, recorremos ao site de buscas "Google" a fim de descobrir quais eram os sites mais

\footnotetext{
${ }^{1}$ Para uma discussão detalhada de cada um desses trabalhos, sugerimos a leitura de Carvalho (2006).
} 
solicitados para ensino de língua portuguesa como língua materna na web. Além dos sites já conhecidos, encontramos o endereço www.oblogdojanio.com. Embora não fosse de nosso interesse, posto que não pretendíamos trabalhar com blogs, por curiosidade resolvemos acessá-lo, e o que encontramos rendeu reflexões que desejamos compartilhar a respeito do seguinte post:

\section{Curso de português gratuito pela internet}

Acabo de ver que minha amiga Cris Zimermann divulgou a notícia de um Curso Gratuito de Português pela Internet. Vá lá e confira. A meu turno, vou mandar uns e-mails divulgando a informação para alguns amigos $e$ amigas que acham que o certo é "agente faz", ao invés de "a gente"; "a impressora imprimi"; "nada haver"; "à quilômetros daqui"; e que têm uma "opnião" muito forte para admitirem que estão errados.

O post obteve sessenta e sete respostas divididas entre pedidos de informações sobre o curso, críticas ao não entendimento do texto de abertura por parte de alguns internautas e interferências do autor do blog. Nosso interesse nas respostas dadas se deve a dois principais motivos: o primeiro é questionar o que leva um usuário escolarizado a procurar um curso do idioma que é sua língua materna, pergunta análoga à feita por Travaglia (1997, p. 17): “Ao dar aula de uma língua para falantes nativos dessa língua é sempre preciso perguntar: 'Para que se dá aulas de uma língua para seus falantes?' ou, transferindo para o nosso caso específico, 'Para que se dá aulas de Português a falantes nativos de Português?"”.

O segundo motivo do nosso interesse pelas expectativas das pessoas em relação ao curso deveu-se também ao fato de acreditarmos que a análise das expectativas dos alunos/internautas nos permitiria levantar hipóteses sobre os conteúdos que poderíamos encontrar nos sites, pois, na internet existe forte relação entre a procura e a oferta de determinados conteúdos. Diferentemente do livro didático, por exemplo, que, mais recentemente, tem sido submetido a avaliações de especialistas antes de ser disponibilizado para o aluno da escola pública, os sites que conseguem se manter são os que têm boa aceitação entre o público, manifesta através dos acessos, o que nem sempre pode ser tomado como bom indicador, pois, como nos alertam Carvalho et al. (2004, p. 2), “um grande interesse pelo público de um site não é sinônimo de qualidade”.

Na tabela 1, abaixo, sintetizamos as 67 respostas oferecidas ao post acima mencionado.

\section{Tabela 1}

\begin{tabular}{|c|l|c|c|}
\hline $\begin{array}{c}\text { PROPÓSITO } \\
\text { DISCURSIVO }\end{array}$ & EXEMPLO(S) & TOTAL & $\%$ \\
\hline $\begin{array}{c}\text { Obter informações } \\
\text { procedimentais }\end{array}$ & $\begin{array}{l}\text { Oi, gostária de participar do curso gratuito de português } \\
\text { pela internet. Como que é feito o cadastro? }\end{array}$ & 40 & 61 \\
\hline $\begin{array}{c}\text { Obter bons resultados em } \\
\text { concursos, arrumar } \\
\text { emprego, ter bom }\end{array}$ & $\begin{array}{l}\text { Estou interessado em participar deste curso de português } \\
\text { para obter bons resultados em concursos públicos. Uso o }\end{array}$ & 6 & 9 \\
\hline
\end{tabular}

\footnotetext{
${ }^{2}$ Preservamos a grafia do texto tal qual encontrada no ambiente virtual.

${ }^{3}$ Preservamos a grafia dos textos semelhante à que encontramos no ambiente virtual.
} 


\begin{tabular}{|c|c|c|c|}
\hline $\begin{array}{l}\text { desempenho nas atividades } \\
\text { profissionais }\end{array}$ & $\begin{array}{l}\text { Windows XP IE } 7 . \\
\text { Ola !!! } \\
\text { Gostaria de saber informações sobre o curso de portugues. } \\
\text { eu,quero fazer p/ facilitar meu trabalho ,falar bem,colocar } \\
\text { corretamente as palhavras no momento certa ,e certa do } \\
\text { que esta falando. } \\
\text { boa noite quero faser um curso gratuito gostaria de saber } \\
\text { como que eu fasso, porque eu naõ sou muito boa no } \\
\text { portugues, naõ sei escrever direito pesso ajuda de vcs pra } \\
\text { mim ajudar porque eu tenho que arumar um emprego, } \\
\text { pesso pelo amor de deus pra vcs mim ajudar, vou esperar } \\
\text { aresposta de vcs anciosamente obrigado. }\end{array}$ & & \\
\hline $\begin{array}{l}\text { Entender melhor a língua } \\
\text { portuguesa }\end{array}$ & $\begin{array}{l}\text { Quro enteder melho a lingua poutuguesa por favô m ajude } \\
\text { ok }\end{array}$ & 1 & 1 \\
\hline $\begin{array}{l}\text { Aperfeiçoar o português/ } \\
\text { gramática/ortografia/ } \\
\text { interpretação }\end{array}$ & $\begin{array}{l}\text { quero fazer o curso pos quero aperfeiçoar o meu português } \\
\text { Oi eu preciso muito aprender a falar e escrever } \\
\text { corretamente o português, como faço para participar desse } \\
\text { curso gratuito. } \\
\text { Abraços. }\end{array}$ & 6 & 9 \\
\hline $\begin{array}{l}\text { Estudar o português como } \\
\text { língua estrangeira }\end{array}$ & $\begin{array}{l}\text { Hola quiero aprender portugues mi msn es: } \\
\text { <editado> } \\
\text { si quieres te puedo ensenar espanol o frances boa noite } \\
\text { jejejejje bye...... }\end{array}$ & 1 & 1 \\
\hline $\begin{array}{l}\text { Criticar os comentários } \\
\text { postados pelas pessoas }\end{array}$ & $\begin{array}{l}\text { Depois de ler estes comentários, só me resta dizer: } \\
\text { kedureza! } \\
\text { Será que ninguém lê o que acessa, ou será o desejo } \\
\text { incontrolável de preencher um formulário qualquer que } \\
\text { seja ele? }\end{array}$ & 9 & 14 \\
\hline $\begin{array}{l}\text { Realizar intervenções como } \\
\text { moderador (Jânio) }\end{array}$ & $\begin{array}{l}\text { É incrível como as pessoas não conseguem interpretar um } \\
\text { texto simples. Eu não sei de curso nenhum, gente, apenas } \\
\text { fiz um comentário sobre um artigo em um outro blog! É } \\
\text { muito mais fácil clicar no link do que escrever comentário } \\
\text { pedindo informações pra mim! }\end{array}$ & 3 & 4 \\
\hline Fazer uma "brincadeira” & $\begin{array}{l}\text { Oi mosso! Poço faser esi curso tambêm? Eu naum cei falar } \\
\text { muinto bem esse tar di portuguêis ... cê mi insina? } \\
(\text { Abração!) }=)\end{array}$ & 1 & 1 \\
\hline
\end{tabular}

\section{Tabela 1: Quantitativo de respostas apresentadas ao post, segundo seu propósito discursivo.}

Além de possibilitar uma previsão do que podemos encontrar nos sites, a análise das respostas dadas pelos internautas nos permite tecer algumas considerações sobre 0 ensino de língua materna no Brasil de modo mais amplo. Uma interpretação possível é a de que o sistema regular de ensino não tem conseguido disponibilizar o conjunto de informações desejadas por seus usuários, pois, excetuando-se o caso da aluna que se declara estrangeira, é possível supor que todas as demais pessoas tenham a experiência de estudar português no sistema regular. Mesmo assim, sentiram a necessidade de complementar sua formação fora do espaço escolar.

Outra conclusão a que podemos chegar é que, de fato, boa parte dos usuários da rede apresenta dificuldades de interagir no ambiente do blog, seja porque, realmente, têm problemas de compreensão de textos, como denunciam alguns dos internautas, ou, porque desconhecem a regra de primeiro ler o texto de abertura do tópico antes de respondê-lo. Admitida essa possibilidade, somos forçados a concordar com teóricos que 
apontam o letramento digital como uma das prioridades do ensino na sociedade moderna. Nas palavras de Braga (2004, p. 161): "É necessário que a escola passe a se preocupar com a formação de leitores para esse novo meio [o ambiente virtual], oferecendo aos alunos práticas pedagógicas que demandem o letramento digital e também formem leitores autônomos”.

Finalmente, os motivos explicitados por alguns internautas nos revelam que a escola tem sido eficiente no sentido de difundir uma visão equivocada de que os falantes comuns, aqueles que não são escritores renomados nem detentores de grande erudição, são usuários incompetentes de uma língua difícil e inacessível. É o que concluímos a partir da leitura da resposta que catalogamos como "brincadeira" na tabela e abaixo reproduzida:

“Oi mosso! Poço faser esi curso tambêm? Eu naum cei falar muinto bem esse tar di portuguêis cê mi insina?

(Abração!) =)"

Ao analisar discursos semelhantes de usuários da língua portuguesa, Lara (2004, p. 157) discute as prováveis causas e os efeitos dessa imagem recorrente no senso comum. Nas palavras da autora:

Essa imagem da língua, que traz como correlata a imagem do usuário, julgado pela sua performance lingüística (“correta” ou "incorreta”), resulta, em parte, de um tipo de ensino falho, lento, distante da realidade do falante, ensino esse que, através de aulas cansativas e métodos pouco atrativos, privilegia a teoria e a memorização de regras gramaticais, esquecendo-se da leitura e da produção de textos variados (inclusive orais). Essa situação se agrava ainda mais com o despreparo do professor e com o desinteresse do aluno, que, não se sentindo motivado a aprender a gostar da língua, não se torna um leitor crítico, um escritor competente e, muito menos, um "bom” falante.

\section{Análise de três sites que oferecem ensino de português}

Após fazermos um levantamento de cerca de dez sites disponíveis para o estudo de português como língua materna na web, submetemos os sites a uma primeira análise com o objetivo de verificar sua estabilidade na rede, os tipos de conhecimentos que ofereciam, as atividades que propunham, seus aspectos gráficos e a média diária de internautas que os acessavam. Posteriormente, nos inscrevemos como alunos em três desses sites e passamos a acessá-los regularmente durante dois meses (agosto a outubro de 2007), tendo o cuidado de realizar as tarefas solicitadas, as leituras indicadas e as avaliações oferecidas. No final desse período, percebemos algumas tendências adotadas pelos sites quanto aos objetivos perseguidos e à concepção de língua adotada, que passaremos a discutir.

\section{www.portugues.com.br}

A primeira tendência que encontramos em sites para ensino de português é representada, neste estudo, pelo endereço "www.portugues.com.br". Ele possui um forte apelo comercial, atestado desde seu aspecto visual saturado de banners e anúncios. Em função desse objetivo, tem pouco conteúdo disponível para pesquisa gratuita. Na 
verdade, ele apenas oferece "dicas" de português do tipo: "conheça a etimologia da palavra...”, "grafe corretamente” etc. Ainda que o site não traga atividades auxiliares à aprendizagem dos tópicos que aborda, tais como exercícios, fóruns de discussões ou qualquer outro recurso que possa indicar uma proposta consistente de ensino de língua, podemos dizer, em função das "dicas” que apresenta, que o site orienta-se por uma concepção de língua como estrutura, um sistema de regras que funciona de modo autônomo.

O que se constata, em sites dessa natureza, é que a exposição das informações sobre a língua funciona apenas como um chamariz para captar a atenção dos internautas para produtos relacionados com os conhecimentos veiculados e que o site tem interesse em anunciar, a saber, livros, gramáticas, revistas e similares.

\section{www.brasilescola.com}

Uma segunda tendência encontrada, bem representada pelo "www.brasilescola.com”, foi a de sites cujo objetivo principal é comercializar o ensino (no site anteriormente analisado, o foco básico está na comercialização de materiais), tanto de português, como de outras disciplinas. Como estratégia para chamar a atenção de seus potenciais consumidores, eles disponibilizam algum material para consulta gratuita, mas, depois que o internauta esgota as primeiras seções, descobre que só poderá prosseguir nos estudos, se “comprar o pacote de conhecimento disponível”.

Também esse site se pauta, majoritariamente, pela concepção de língua enquanto sistema de regras, passível de fixação e de sistematização em dicionários e gramáticas. Ainda que faça referência à gramática descritiva, o faz de modo superficial, deixando transparecer que a atenção maior do site está direcionada para a gramática normativa. Observemos um dos artigos nele veiculados:

Mas o que vem a ser gramática?

Segundo o dicionário Houaiss, quer dizer "conjunto de prescrições e regras que determinam o uso considerado correto da língua escrita e falada”. Em outras palavras, gramática é o conjunto de leis que regem a língua de um povo. Nesse contexto, há, lingüisticamente falando, dois tipos de gramática: a que vem da cultura, do ambiente social do povo, que não se prende às regras, mas vem do ambiente em que o falante desenvolve suas atividades diárias de comunicação e expressão, que é chamada de gramática descritiva. É comum, nesse tipo de gramática, frases do tipo "a gente fizemos tudo que podia”, ou, "eu vi ela entrando pra dentro do carro". "Por ser de natureza científica, não está preocupada em estabelecer o que é certo ou errado no nível do saber idiomático”, e sim na relação adequado ou inadequado. O outro tipo, que é cheio de regras, nas quais se baseia a variedade padrão da língua, também chamada de norma culta, é a gramática normativa. Esse último é que é a base das provas de língua portuguesa de concursos. Também é o tipo adotado e explicado nas gramáticas e ensinado nas escolas. Aqui, sim, cabe uma preocupação quanto ao que é certo ou errado dentro do campo da comunicação pelo seu caráter totalmente pedagógico, pois agora há um respaldo de renomados escritores de nossa literatura e de dicionaristas esclarecidos, segundo afirmou Bechara em sua Gramática Escolar da Língua Portuguesa.

O que propomos nesses encontros com a língua portuguesa é levar os internautas a uma reflexão de como o nosso idioma tem sido falado e escrito por esse "Brasilzão".

Evitaremos, portanto, manifestar nossa opinião sobre determinado ponto gramatical; quando o fizermos, assinalaremos com uma nota que demonstrará a 
nossa posição referente ao assunto em estudo.

Então temos um encontro marcado aqui para discutirmos, conversarmos, analisarmos e tiramos dúvidas sobre a nossa língua portuguesa.

Um cordial abraço,

Prof. Luiz Mesquita (Lewry). ${ }^{4}$

Uma análise do texto, ainda que breve, nos permite constatar um conjunto de afirmações pouco claras e mesmo equivocadas a respeito do estudo da linguagem. Assim, após apresentar a definição do dicionário Houiass para gramática ("conjunto de prescrições e regras que determinam o uso correto da língua escrita e falada”), o autor do artigo se encarrega de traduzi-la para "o conjunto de leis que regem a língua de um povo”, paráfrase que, além de não ajudar a compreender a definição de Houiass, enfatiza, sobretudo, “o conjunto de leis”. Duas linhas adiante, no entanto, o texto irá falar de um tipo de gramática "que vem da cultura, do ambiente social do povo, que não se prende às regras [...], que é chamada de gramática descritiva”. Primeiro, é importante destacar que "toda língua - em qualquer condição de uso - é regulada por uma gramática” (ANTUNES, 2007, p. 27). Quando um falante diz "a gente fizemos tudo que podia”, ou, “eu vi ela entrando pra dentro do carro” (exemplos do autor do artigo), é porque conhece muito da gramática que regula o funcionamento de sua língua. Segundo, mais do que "não se prender a regras", a gramática descritiva "focaliza elementos da estrutura da língua, descrevendo-os apenas ou apresentando-os em suas especificidades” (ANTUNES, 2007, p. 33), ou seja, a gramática descritiva também irá se ocupar de frases como "eu o encontrei no cinema", desde que veiculadas pelos usuários.

A definição de gramática normativa como um tipo de gramática "cheio de regras" é associada a argumentos que apontam para o que se considera o uso correto da língua, pois essa gramática "é a base da provas de língua portuguesa de concursos"; "é o tipo adotado e explicado nas gramáticas [quais?] e ensinado nas escolas"; recebe "um respaldo de renomados escritores de nossa literatura e de dicionaristas esclarecidos, segundo afirmou Bechara em sua Gramática Escolar da Língua Portuguesa”. Essa é a gramática que o site, efetivamente, quer ensinar, pois a promessa de evitar "manifestar nossa opinião sobre determinado ponto gramatical” feita pelo autor do artigo, sugerindo uma reflexão mais direcionada para "como o nosso idioma tem sido falado e escrito por esse 'Brasilzão'” é totalmente ignorada, já que os fenômenos que ele, de fato, trabalha são apenas aqueles previstos pela gramática tradicional.

\section{www.cursinhoweb.com.br}

Este site exemplifica outra tendência, encontrada em número menos frequente de ensino de língua materna na web. Ele apresenta uma proposta sistemática de ensino de português, sobressaindo-se dentre os demais sites analisados quanto à consistência das atividades encaminhadas. Nesse, o aluno precisa efetuar sua matrícula, acessar um tempo mínimo de aulas, realizar os exercícios e as avaliações indicadas. Além disso, o internauta dispõe de recursos tais como fóruns, chats e ainda da possibilidade de receber material impresso em sua residência, embora tenha que pagar pelo mesmo.

\footnotetext{
${ }^{4}$ Disponível em: http://www.brasilescola.com/gramatica. Acesso em: 15 ago 2007. Preservamos a grafia encontrada no ambiente virtual. A formatação do texto aqui adotada sofreu pequenos ajustes em relação à identificada no site.
} 
Contudo, o site comete o equívoco de confundir língua portuguesa com a gramática normativa tradicional, embasando-se na mesma concepção de língua enquanto sistema recorrente nos outros sites já apresentados. Assim, o curso de língua portuguesa resume-se a uma sequência rígida de conteúdos que vai dá fonética à sintaxe, semelhantemente ao ensino tradicional regular bem descrito pelos seguintes autores:

No âmbito de ensino de gramática, aborda-se a análise fonética e morfossintática de palavras e expressões no $1^{\circ}$ ano do $\mathrm{EM}^{5}$, como revisão do $1^{\circ}$ ciclo do $\mathrm{EFII}^{6}$ ( $5^{\mathrm{a}}$ e $6^{\mathrm{a}}$ séries); introduz-se a análise sintática dos períodos, agora com orações reduzidas, no $2^{\circ}$ ano do EM, revisando-se o $2^{\circ}$ ciclo do EFII $\left(7^{\mathrm{a}} \mathrm{e}\right.$ $8^{a}$ séries ); etc. O $3^{\circ}$ ano do EM seria mais dedicado a uma revisão geral de todo o currículo escolar, com ênfase no treinamento para o vestibular, situação mais comum em escolas privadas. (MENDONÇA, 2006, p. 4)

Os exercícios de reconhecimento e classificação de classes de palavras e de funções sintáticas correspondem a mais de 70\% (75,56\%) das atividades de ensino de gramática, aparecendo em todos os grupos de professores pesquisados. Confirma-se, pois, a afirmação inicial de que os mesmos tópicos gramaticais são repisados ano após ano, pelos onze anos que constituem o ensino de $1^{\circ}$ e $2^{\circ}$ graus. $^{7}$ (TRAVAGLIA, 1997, p. 103)

Atualmente, já existe um consenso apoiado por teóricos como Antunes (2007), Bagno (2002), Possenti (1996), entre outros, de que tal ensino é insuficiente no sentido de instrumentalizar o aluno das competências necessárias para a convivência na moderna sociedade grafocêntrica atual, tendo em vista que ele promove um saber sobre a língua, conhecimento relevante para a formação de analistas, mas que não representa uma grande contribuição para a formação de usuários competentes da língua.

\section{Conclusões}

A internet é uma fonte privilegiada de pesquisa e estudo da língua materna, entretanto, devido à ausência de políticas reguladoras dos auto-intitulados sites educativos, observamos contradições entre os objetivos declarados e o material neles disponibilizado: alguns prestam-se, principalmente, à promoção de produtos relacionados ao ensino; em outros, a própria língua é tratada como um produto.

Entre aqueles sites que realmente oferecem um ensino sistemático, predomina uma visão na qual a língua é tomada como um sistema de regras não problemático e capaz de funcionar com transparência e homogeneidade, desvinculada dos usuários, deslocada da realidade, semanticamente autônoma e a-histórica. Consequentemente, a gramática é vista como um conjunto de prescrições que fixa o uso da norma culta.

Tal percepção não invalida a afirmação de estudos recentes de que os recursos disponibilizados pela internet podem representar contribuições ao processo de ensino/aprendizagem. Contudo, alerta-nos, enquanto professores de português, para a necessidade de observar critérios de qualidade tais como: autoria, idoneidade da instituição e/ou pessoa pública, aspectos gráficos do site, e, principalmente, os objetivos

\footnotetext{
${ }^{5}$ Leia-se Ensino Médio.

${ }^{6}$ Ensino Fundamental - segunda etapa.

${ }^{7}$ Grifo nosso.
} 
e as concepções que orientam as atividades propostas pelo site antes de adotarmos tal instrumento como recurso para o ensino/aprendizagem de língua materna.

\section{Referências}

ANTUNES, Irandé. Muito além da gramática: por um ensino de línguas sem pedras no caminho. São Paulo: Parábola Editorial, 2007.

BAGNO, Marcos. A inevitável travessia: da prescrição gramatical à educação lingüística. In: et al. Língua materna: letramento, variação e ensino. São Paulo: Parábola Editorial, 2002. p. 13-82.

BRAGA, Denise Bértoli. A comunicação interativa em ambientes hipermídia: as vantagens da hipermobilidade para o aprendizado no meio digital. In: MARCUSCHI, Luiz A.; XAVIER, Antonio C. (Orgs.). Hipertexto e gêneros digitais: novas formas de construção de sentido. Rio de Janeiro: Lucerna, 2004. p.144-163.

CARVALHO, Ana Amélia A. et al. Indicadores de qualidade e de confiança de um site. In: ALVES, M. P.; MACHADO, E. A. (Eds.). Actas das II Jornadas da Secção Portuguesa da ADMEE: A avaliação e a validação das competências em contextos escolares e profissionais. Braga, Portugal: CIED, IEP, 2004.

CARVALHO, Ana Amélia A. Indicadores de qualidade e de confiança de um site educativo. Cadernos SACAUSEF - Sistema de Avaliação, Certificado e apoio à utilização de software para educação e a formação, Portugal: Ministério da Educação, n. 2, p. 55-78, 2006.

DOTTA, Sílvia Cristina. Análise de um site educacional: o exemplo do projeto descobrir e viver a cidade de São Paulo. Mimeo, 2003.

FRANCO, Dulce. Um olhar sobre o site. Tecnologias em educação: estudos e investigações. Lisboa. Mimeo, 2000.

LARA, Graça M. P. O que dizem da língua os que ensinam a língua. Campo Grande: Ed. UFMS, 2004.

LÉVY, Pierre. Cibercultura. Lisboa: Instituto Piaget, 2000.

POSSENTI, Sírio. Por que (não) ensinar gramática na escola. Campinas: Mercado de Letras: Associação de Leitura do Brasil, 1996.

SANTOS, Elisa Martins dos. Pesquisa na Internet: copia/cola. In: ARAÚJO, J. C. Internet e ensino: novos gêneros, outros desafios. Rio de Janeiro: Lucerna, 2007. p. 268-279.

HOUAISS, Antonio. Dicionário Houaiss da língua portuguesa. Rio de Janeiro: Objetiva, 2001. 
TRAVAGLIA, Luiz Carlos. Gramática e interação - uma proposta para o ensino de gramática no $1^{\circ}$ e $2^{\circ}$ graus. 2. ed. São Paulo: Cortez, 1997.

VIDAL, Elisabete. Ensino à distância vs ensino tradicional. Monografia, Universidade Fernando Pessoa. Porto, Mimeo, 2002. 